\title{
EDITORIAL
}

\section{Reflecting on the first two years of journal AERE}

\author{
Editor-in-Chief: Sergei Abramovich
}

School of Education and Professional Studies, State University of New York, Potsdam, USA

\section{Check for updates}

Correspondence to: Sergei Abramovich, School of Education and Professional Studies, State University of New York, Potsdam, USA;

E-mail: abramovs@potsdam.edu

Received: December 9, 2021;

Published: December 9, 2021

Citation: Abramovich S. Reflecting on the first two years of journal AERE. Adv Educ Res Eval, 2021, 2(2): years of jourt $188-190$.

https://doi.org/10.25082/AERE.2021.02.005

Copyright: () 2021 Sergei Abramovich. This is an open access article distributed under the terms of the Creative Commons Attribution License, which permits unrestricted use, distribution, and reproduction in any medium, provided the original author and source are credited.

\section{(c) (7) (8)}

This editorial is written to reflect on the first two years of AERE. Shortly after the launch of the journal at the end of 2019, the pandemic hit the globe and it continues affecting everything world-wide as the year 2021 comes to an end. Some people believe the pandemic increased their scholarly productivity; others are of the opposite opinion. Regardless, over the span of two years, 2020-2021, the journal published 21 articles which collectively, by the time of writing this editorial, enjoyed 18,804 Abstract and 9,788 PDF downloads. One can see almost two to one ratio between the two types of downloads. Whereas this ratio is consistent with the Article Access Statistics of a sister journal, Advances in Developmental and Educational Psychology (ADEP), published by SyncSci Publishing over the period of three years (2019-2021), the articles published by ADEP, by the time of writing this editorial, enjoyed 8898 and 4310 Abstract and PDF downloads, respectively. Thus, comparing the total number of both types of downloads for the two journals, the ratio is also about two to one in favor of AERE. Statistics for another sister journal, International Journal of Arts and Humanities (IJAH), also in existence since 2020, is represented by 4961 and 3043 downloads for Abstract and PDF, respectively. While the ratio of the two numbers is smaller than two (1.6), another ratio comparing AERE and IJAH is much larger than two (3.6) in favor of AERE. This access statistics data for the first two years indicates a fairly successful state of affairs with AERE as a new scholarly outlet and demonstrates its appreciation by those interested in advances that research and evaluation in education transpire around the world.

It should be noted that without educationally diverse and epistemically thorough contributions by our authors - educational researchers from Australia, China, United Kingdom, Denmark and the United States - the journal would not have enjoyed such relatively high level of downloads. Not a small measure of this success is the diligent work of the AERE Editorial Board that consists of 22 members representing Australia, China, Cyprus, Greece, Iran, Japan, Lebanon, Republic of Korea, Spain, Thailand, Turkey and the United States, as well as many other experts in the discipline of education who volunteered their time to do peer review at the request of Snowy Wang, the Managing Editor of AERE. As Editor-in-Chief, I would like to take this opportunity to express my sincere gratitude to our authors, editorial board members, reviewers, and Ms. Wang.

As I worked on my reflections, I re-read the papers we published. A series of papers has been published in 2020 by educational researchers from Texas, United States, using inferential statistics approach and providing research-based suggestions for educational policy and practice. These papers include the study of the dependence of social skills on the gender of students, investigation of the assignments designed for middle school male students placed into the Disciplinary Alternative Education Program (DAEP) as the function of their ethnicity and race, the study of mathematical performance of grades 3 through 8 special education students placed in DAEP, and the inquiry into the one-year persistence rated of Hispanic students in community colleges in Texas. Co-authored by researchers from Arizona and Texas, a related study was published (2021, \#2) about humanizing community college experiences of Mexican American students by helping them to connect their cultural background with current educational endeavors. This study provides important implications for faculty, staff, and administrators of community colleges that enroll students of Mexican descent. 
A series of papers reflected on programs educating students in the science of medicine across a number of universities in the United States. The papers included the investigation of the effect of the so-called flipped classroom approach on the education of the second-year medical students in the context of studying pharmacology and pathology topics in the endocrine and reproductive parts of a medical program. Within this approach, the students were supposed to study independently prior to attending face-to-face classrooms. A related medical research paper (2020,\#2) dealt with the inquiry into the use of a web-based Audience Response System known as Mentimeter (https://www.mentimeter.com/) in a medical physiology course. By analyzing student evaluations of the course, the authors, representing three medical schools, found this tool to be appreciated by students as an instrument clarifying complicated concepts during their exam preparation. The authors recommended the tool to be used by instructors in both preclinical and clinical learning contexts. Another paper (2021, \#2) suggested that innovations in medical education make it challenging for instructors to take full advantage of the traditional medical education. The authors of this paper, faculty members of a recently (2018) founded allopathic medical school, shared ideas about achieving the right balance between using the new and the old teaching approaches. The ideas include careful and continuous consideration of student feedback and creating conditions for productive faculty-student partnership.

Several publications were devoted to psychological issues arising in education. One study was published (2021, \#2) by a scholar from United Kingdom concerning "psychological and academic trust alienation theory". Another study concerned teacher self-efficacy characterizing Danish teachers' beliefs about their ability to advance students' learning (2021, \#2). Researchers from China studied the influence of the revival of Chinese cultural heritage on the language development of young children (2021, \#1). Back to Europe, emotional experience of schoolchildren in United Kingdom during their transition from the primary to the secondary classroom was a topic of another publication (2021,\#1). Finally, challenges of managing students' behavioral problems in American schools were discussed in a paper $(2021, \# 1)$ that shares three decades of experience by the author.

Researchers from the United States studied (2021, \#1) differences in students' learning styles across different subject matters and provided recommendations for the design of interprofessional education courses suggesting that the attributes of learning must be interwoven both tacitly and directly into the learning experiences of students. An interesting study $(2020, \# 2)$, demonstrating an effect that school funding, teachers' experience, and student-teacher ratio have on the achievement of students. The three characteristics were studied in terms of a short-term and long-term effect on the achievement of schoolchildren. Funding per students was found to be not as important (at least in short-term) as other two characteristics. In another context of pre-college education, a researcher from Australia (2020, \#1) studied the so-called mastery goal states of grade 10 students with a positive goal state "wanting to learn". Through this study, it was discovered that some students reported "not wanting to learn" as their mastery goal state. This was referred to as a negative mastery goal state, being as significant as a positive mastery goal state.

Teaching psychology at the graduate level was compared through the lenses of two $20^{\text {th }}$ century philosophical approaches to science education - the approach by Paul Feyerabend (known for his repudiation of the use of general systematic standards) and that of Thomas Kuhn (who argued for the non-linear character of the progress of science that goes, instead, through what he called "paradigm shifts"). The study (2020, \#2) favored the philosophy of Kuhn and suggested the expansion of the findings to teaching graduate courses in STEM disciplines. The same author published a paper (2021, \#1) dealing with the use of student evaluations of teaching as a way of improving teaching effectiveness of university faculty and the learning of students. The study provided psychometric implications for understanding the relationship between reliability and validity of traditional evaluations of teaching.

To conclude my reflections on the first two years of AERE, I would like to encourage our authors to continue supporting the journal by publishing with us their wonderful 
papers and, as a way of expanding coverage to new disciplines and subject matters, to welcome high-quality submissions from STEM education researchers. 